\title{
Perceptions of South African National and Provincial Health Directorate managers on eye health promotion
}

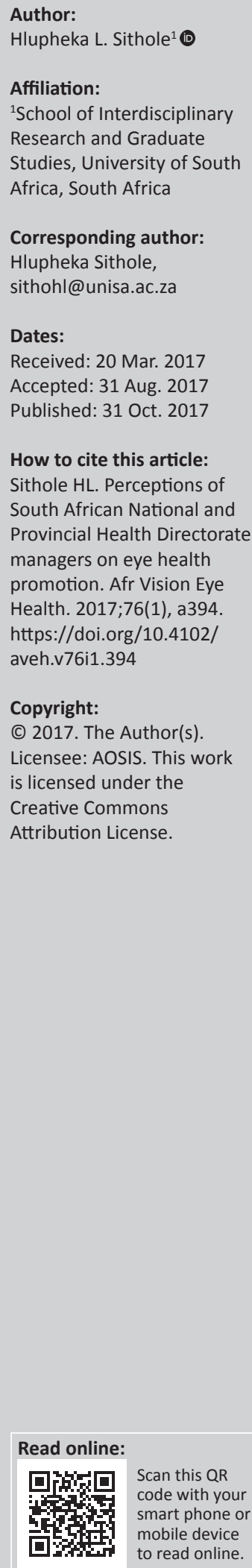

Background: Health directorate managers are responsible for health promotion initiatives in South Africa.

Purpose: This study sought to establish the perceptions of health managers in the various health directorates regarding eye health promotion activities in the country.

Methods: The study used structured interviews as a tool for collecting relevant information on the perceptions of health directorate managers about eye health promotion. Six managers from the National Department of Health and 53 from the Provincial Health Directorates were interviewed.

Results: The provincial managers from the Directorates of Chronic Diseases, Disabilities and Geriatrics $(N=8)$ indicated that their policies included eye health issues. Those from other directorates $(N=45)$ indicated that no reference was made to eye health in their provincial policy documents for health promotion. However, they all believed that eye health promotion messages or some elements of eye health promotion should be integrated in their programmes.

Conclusion: Although there is a draft policy framework for eye healthcare, the lack of a dedicated directorate and poor capacity in the National Department of Health is likely to retard the progress of implementing policy directives.

\section{Introduction}

Most developing countries have integrated health promotion into their Primary Health Care (PHC) systems to expedite the delivery of healthcare services, ${ }^{1}$ including South Africa. Unfortunately, despite the World Health Organization's ${ }^{2}$ recommendation for integrating eye health promotion and eye care into the PHC approach, South Africa seems to have done little so far in this area. ${ }^{3}$ However, it is encouraging that the role of health promotion in the public health initiatives has gained popularity in blindness prevention organisations in order to attain Vision 2020: The Right to Sight goals primarily and the United Nation's Millennium Development Goals indirectly. ${ }^{4}$ It is, therefore, expected for the South African National Department of Health to observe the directives of these organisations by ensuring that matters of eye health promotion are emphasised in consistence with the Ottawa Charter.

The Ottawa Charter ${ }^{5}$ highlighted the need for health issues to be placed onto policy agendas for decision-making at various levels of healthcare development. Also, the Jakarta Declaration ${ }^{6}$ reiterated the need for committed social responsibility, expanded partnerships in health and increased focus in community empowerment. Furthermore, the Durban Declaration ${ }^{4}$ on refractive error and service development has added its weight in calling for the blindness prevention community to establish eye care programmes that will deliver tangible results in eye health promotion. Unfortunately, with no dedicated directorate for eye healthcare issues and lack of eye healthcare policy, eye health promotion continues to be underemphasised in South Africa.

Sithole ${ }^{3}$ reported that most health directorates in the South African National Department of Health organise health promotion activities for other health priority areas but mostly excluding eye health promotion. This study, therefore, sought to establish the perceptions of health managers in the various national and Provincial Health Directorates on eye health promotion activities in South Africa with a view to strengthening recommendations for the establishment of an independent eye healthcare directorate and the development of an integrated eye health promotion policy.

Note: This article is partially based on the author's thesis for the degree of Doctor of Literature and Philosophy in Health Studies at the University of South Africa, South Africa, with supervisor Prof. O.N. Makhubela-Nkondo and co-supervisor Prof. O.A. Oduntan, received May 2013, available here: http://uir.unisa.ac.za/bitstream/handle/10500/11833/thesis_sithole_hl.pdf?sequence=1 


\section{Methods Study design}

The study used structured interviews (Appendix 1) as a tool for collecting information needed to establish the perceptions of health managers in the various health directorates on eye health promotion activities in South Africa. The researcher conducted the interviews with all participants following a pretesting of the data collection instrument. The study sites were the National Department of Health and all nine Provincial Departments of Health in South Africa. The participants included all managers of the following directorates: National and Provincial Directorates of Chronic Diseases, Disabilities and Geriatrics; Health Promotion; Integrated Nutrition Services; Mental Health, HIV and AIDS; Youth Health; and Maternal, Child and Women's Health. These managers were selected because their directorates are responsible for health promotion activities across the country and it was, therefore, important to establish their perception on eye health promotion activities.

\section{Ethical considerations}

This study was approved by the Health Studies Research and Ethics Committee of the University of South Africa. Permission to conduct the study was obtained from the relevant government authorities before the commencement of the study. All the ethics protocols were observed before, during and after the study.

\section{Data management and analysis}

Data were decoded from the tapes used during interviews and analysed using ATLAS.Ti7 research software for qualitative research.

\section{Results \\ Directorate managers}

Six managers from the National Department of Health and 53 from the Provincial Health Directorates were interviewed. Therefore, a total of 59 health officials were included in the study.

\section{National health directorates' managers \\ Presence of eye health promotion policy}

During the interviews, it was established that there were eye healthcare guidelines that were not policies and as such could not be easily integrated into health promotion activities of other health directorates because of lack of a clear strategy. This was confirmed by a respondent from the Directorate of Chronic Diseases, Disabilities and Geriatrics who stated that:

The fragmented guidelines on different aspects of eye care exist and should be further developed into one integrated policy from which all provinces can draw their eye health promotion activities. This will enable other directorates to integrate eye health promotion initiatives into their health promotion projects. (Directorate of Chronic Diseases, Disabilities and Geriatrics, National Department of Health)

\section{Integration of eye health promotion activities}

When asked whether statements on eye health issues such as vision screening and eye protection were integrated in their policies for health promotion programmes, the majority (five of six) of the respondents indicated that none of the policies in their directorates made reference to issues of eye health. One respondent from the Directorate of Maternal, Child and Women's Health stated that:

Eye health is not part of our responsibility hence it could not be included in our health promotion policy documents. Therefore, we are not expected to carry eye health messages to the communities. It is the responsibility of one of the directorates. We are not expected to do vision screening. It is not in our policy papers. (Directorate of Maternal, Child and Women's Health, National Department of Health)

\section{Capacity for eye health promotion}

Although representatives from different directorates understood that including eye health promotion proposals, strategies and interventions in eye health policy development could contribute significantly in the improvement of community eye health, they also believed that the lack of capacity and an independent eye healthcare unit will always result in eye health promotion being considered as less important than other health priorities. This is reflected in the following response of a respondent from the Directorate of Mental Health, HIV and AIDS:

The lack of an eye health care directorate in the South African health care system greatly compromises any strategies and programmes for eye health promotion. Also, the obvious lack of dedicated eye health promotion personnel in the provinces is as a result of the lack of an integrated policy in eye health promotion. As the economic hub of this continent, we were supposed to be playing a leading role in eye health promotion but then again, the lack of advocacy for eye health promotion funding will always be a hindrance and as a result community eye health will suffer as well as the African continent. (Directorate of Mental Health, HIV and AIDS, National Department of Health)

\section{Roll-out of eye health promotion activities in the communities}

A respondent from the National Directorate of Health Promotion believed that health promotion in South Africa was still a relatively new concept as a health discipline and, as a result, different provinces carried out their health promotion activities differently. The respondent further indicated that in order to improve the delivery of health promotion in South Africa, community engagement and participation must be encouraged. This was shown in this response:

For any health promotion strategy to be successful, community engagement and participation is crucial. Skills development and multi-sectoral collaboration could greatly improve the delivery of health promotion in South Africa. Furthermore, other important aspects for successful delivery of health promotion must include the need to improve health literacy, improve community participation and promote public-private partnerships. In this way, our limited resources as government will be supplemented by the private sector and in that manner, 
health promotion and health care will not only be the responsibility of government. (National Directorate of Health Promotion, National Department of Health)

\section{Provincial level health directorate managers Integration of eye health promotion strategies}

The managers from the Provincial Directorates of Chronic Diseases, Disabilities and Geriatrics $(N=8)$ indicated that their policies included eye health. Those from the other directorates $(N=45)$ indicated that no reference was made to eye health in their provincial policy documents for health promotion. However, they all believed that eye health promotion messages or some elements of eye health promotion could be integrated in their programmes. For example:

Eye health promotion messages may assist in enriching our programmes but there may be a need for training of staff members who will be responsible for carrying out this mandate. Otherwise, although we see the importance of eye health promotion messages in our programmes, at the moment the lack of trained staff makes it difficult to do this. (Mental Health and HIV / AIDS Unit, Eastern Cape Province)

The other respondents from various directorates believed that eye health promotion messages could only be integrated in their health programmes once the Provincial Directorate of Chronic Diseases, Disabilities and Geriatrics had made an initiative of ensuring that such messages were part of their programmes. This was also shown in the following quotation:

Eye health promotion messages may be an important aspect of our outreach programmes especially at district level. However, it is important for us to get some guidance from the relevant directorate on how to carry such messages forward. (Integrated Nutrition Services, North-West Province)

Furthermore, all other respondents believed that the only way through which they could give support for eye health promotion in the provinces was when there were qualified personnel to carry out such responsibilities. Subsequently, it has also been reported that they were currently unable to do any eye health promotion work in their programmes because of lack of funds and knowledgeable personnel in the area of eye health promotion. This was also shown in these quotations:

The lack of dedicated funds for eye health promotion and personnel trained in eye health promotion makes it difficult to do eye health promotion and is therefore an important barrier in integrating health programmes. Furthermore, the inadequate number of optometrists in the province has always made it difficult to carry out any eye health promotion activities in the province at large. (Health Promotion, Mpumalanga)

We do not even have a single optometrist in the public services so the issue of health promotion will always be hard to integrate with other health promotion programmes due to lack of insightful information from the relevant stakeholders. As it is, there is no eye health promotion activities in our province that are done by any directorate. (HIV / AIDS Unit, Northern Cape Province)

\section{Barriers to integration of eye health promotion activities}

The respondents from the Directorate of Chronic Diseases, Disabilities and Geriatrics in the KwaZulu-Natal and the
Eastern Cape provinces reported that they had minimal barriers to eye health promotion because of the involvement of organisations such as the Brien Holden Vision Institute and Siyabona Sonke in their provinces, respectively. Also, the respondent from the North-West Province also believed that the directorate may benefit from Siyabona Sonke as they have signed a Memorandum of Understanding (MoU) that will include eye health promotion as part of delivering eye care services in their province. This is also reflected in the following responses:

The Brien Holden Vision Institute has assisted in the elimination of most barriers to eye care and health promotion in the province. They have assisted in the training of ophthalmic nurses who work in public hospitals. As a result of this initiative, we see eye health promotion getting some great assistance by this organisation. (Chronic Diseases, Disabilities and Geriatrics, KwaZulu-Natal)

Non-governmental Organisations are ready to play a major role in improving eye health promotion in the province as the Department of Health has recently signed an MoU with Siyabona Sonke which seeks to assist the province with the delivery of eye care in the province especially in the rural areas. As a result of this, most barriers such as lack of funding and inadequate personnel with eye care experience will be eliminated in our province. (Chronic Diseases, Disabilities and Geriatrics, North-West)

\section{Discussion}

\section{Presence of eye health promotion policy}

As a developing country and a leading economy in Africa, it is important for South Africa to develop an integrated eye health promotion policy for the betterment of the provision of eye healthcare services. Currently, there is no eye health promotion strategy in the country. However, it is interesting to note that there is a draft Eye Health Policy Framework and Strategy 2017-2022 ${ }^{7}$ that is being developed within the National Department of Health and it makes mention of eye health promotion as a strategic objective to the goal of reducing avoidable blindness in South Africa. Once enacted into policy, it is expected that the custodians will be in a position to share and integrate useful information with policy makers from other health directorates.

\section{Capacity for eye health promotion}

Sithole $^{3}$ indicated that the lack of appropriate eye care professionals as custodians of any possible integrated eye health promotion programmes is a challenge within the National Directorate of Chronic Diseases, Disabilities and Geriatrics. However, there is a recent appointment of an optometrist within the directorate as a deputy director for eye healthcare issues. This is a positive step towards realigning eye care services in the country. It is believed that the appointee will make a meaningful contribution by ensuring that other cadres of eye healthcare are included into the team responsible for developing the strategic policy for eye care, 2017-2022.

Previously, the lack of an individual with eye care knowledge in the National Directorate of Chronic Diseases, Disabilities 
and Geriatrics meant that the burden of integrating health programmes was left upon the district health personnel. ${ }^{8}$ It is, therefore, not even surprising that there was and there still is no eye health promotion policy in South Africa. Unfortunately, communities are being negatively affected by the lack of a political will to increase the capacity for eye health promotion. For example, the majority of eye care professionals such as optometrists $(N=3187)$ are largely in the private sector, with only $280(8 \%)$ optometrists employed in the public health sector. ${ }^{3}$ However, the envisaged plan for optometrists in South Africa to practice at a maximum threshold of Category 4 (providing optical technology services; visual function services; ocular diagnostic services and ocular therapeutic services), as adopted by the World Council of Optometry, similar to optometrists in the United States, New Zealand, Australia and Nigeria, ${ }^{9}$ may help in improving their geographic distribution, perceptions and attitudes towards eye health promotion.

\section{Integrating health promotion strategies}

In this study, there was a general agreement among health directorates' managers that it was necessary to integrate eye health promotion with other health promotion activities to ensure improved effectiveness and sustainability of eye healthcare. The research evidence suggests that there is a lack of clear understanding among the identified health managers at national and provincial levels on the dynamics, limitations and processes of eye health promotion services delivery. However, this was largely associated with the lack of eye health promotion policy in South Africa. As a result, provinces have no clear directives on how eye health promotion activities will be integrated and who will take the initiative to integrate the programmes.

\section{Barriers to integration of eye health promotion strategies}

The health policy process in South Africa appears to be dominated by power, protection of professional interests and maintenance of autonomy. ${ }^{9}$ National health management decision-making may be driven by political pressure and the need to conform to national policies. Provincial health managerial decision-making on the contrary appears to be driven by protecting professional interests and preserving autonomy. Both levels of decision-making are, therefore, driven by different agendas and influences. This might account for the poor communication between national health planners and provincial managers. ${ }^{10}$ Although this assertion still needs further investigation, contemporary discourse on the separation of medical doctors from the Health Professions Council of South Africa to form their own council is one such example of how professional interest and preservation of autonomy is being placed above critical decision-making that will enhance cooperation by all health disciplines and thus remove barriers to integration of eye health promotion strategies.

A clearer understanding of this phenomenon is also evident when one examines the nature of optometry undergraduate training in South Africa. Optometry degrees are essentially clinical degrees with inadequate eye health promotion components in them. Much emphasis is placed on public health rather than health promotion. Despite efforts by different universities offering the degree and the Brien Holden Vision Institute to improve community eye health research and service delivery, there are no adequate changes in the scope of optometry training to include eye health promotion. As a result, health planners, decision-makers, managers and service providers entering the public health sector would be very much influenced by the biomedical approach to eye healthcare. ${ }^{10}$ Furthermore, there seem not to be enough leaders in eye health that advocate for paradigm shifts in undergraduate training at a higher political level. This is also evident with poor or lack of communication from those who hold power to advocate for improved cooperation between optometrists undergoing therapeutic training and ophthalmologists who should be supervising them. Unfortunately, all these affect how eye health promotion is ultimately rolled out from the national, provincial and up to community levels.

\section{Roll-out of eye health promotion activities in the communities}

In view of the current situation in eye health promotion in the South African PHC system, it is therefore important to consider restructuring health services delivery as a matter of urgency. Although the proposed national health insurance plan may yield some positive results in this regard, changes in eye care and particularly in eye health promotion may take too long to be effected. This may largely be because of the lack of an integrated eye health promotion policy in the Department of Health and appropriate personnel to effect those changes. According to Kelleher, ${ }^{11}$ the complexities and apparent dualities in defining health promotion practice in South Africa have serious complications for health policy development. Although policy and programmatic integration would provide invaluable opportunities to improve eye health-related service delivery, this is insufficient. A shift in paradigm is required to challenge the traditional delivery of eye health promotion and other related primary healthcare efforts. 12,13,14 This shift will have to address issues of how eye health promotion at primary health level should be delivered and will have to include the following:

- Realignment of eye health in the PHC level. This means that primary eye care providers such as ophthalmic nurses and optometrists should be readily available at this level.

- Evaluation of currently existing projects to ensure they incorporate eye health promotion. This may require the involvement of all health directorates that engage in health promotion activities.

- Institution of pilot projects of systematic approaches to health promotion interventions.

- Application of best practices drawn from pilot projects. Evidence-based practice approaches will then have to be adopted. 
Unfortunately, the current delivery of health promotion services in South Africa is largely disorganised and fragmented despite concerted efforts to integrate district health services. Therefore, the development of eye health promotion policy may prove to be a more viable solution to the challenges of eye health promotion.

\section{Conclusion}

Health directorate managers in the different healthcare directorates at both national and provincial levels seem not to have any mandate or adequate information related to eye health promotion. It is also possible that they may be prioritising other health promotion commitments than eye health promotion because of lack of capacity. As a result, eye health promotion may not feature prominently in their health promotion activities. Although their ultimate perceptions are that eye healthcare is an important aspect of health promotion, however, without any clear directives from a non-existent eye healthcare body within the national structures, it is difficult to comprehend how and by whom eye health promotion messages should be carried out. Furthermore, despite the presence of a draft eye health policy framework, the absence of a dedicated eye health directorate will still stifle any progress made. It will therefore be more important that the directorate is expeditiously established and that an integrated eye health promotion policy is developed without delay.

\section{Acknowledgements}

The author would like to acknowledge the National Research Foundation of South Africa and the University of South Africa's Research Department for making it possible for the study to be carried out through their financial support.

\section{Competing interests}

The author declares that he has no financial or personal relationships which may have inappropriately influenced him in writing this article.

\section{References}

1. Hubley J, Gilbert C. Eye health promotion and prevention of blindness in developing countries: critical issues. Br J Ophthalmol 2006;90:279-284. https:// doi.org/10.1136/bjo.2005.078451

2. Hubley J. Communicating health - An action guide to health education and health promotion. 2nd ed. Oxford: Macmillan; 2004.

3. Sithole HL. A situational analysis of ocular health promotion in the South African Primary Health Care System. Clin Exp Optom [serial online]. 2017 [cited n.d.]. Available from: http://onlinelibrary.wiley.com/doi/10.1111/cxo.12452/pdf

4. Naidoo KS, Wallace DB, Holden BA, et al. The challenge of uncorrected refractive error: driving the agenda of the Durban Declaration on refractive error and service development. Clin Exp Optom 2010;93(3):131-136. https://doi. org/10.1111/j.1444-0938.2010.00455.x

5. World Health Organization. Ottawa Charter for Health Promotion. An Internationa Conference on Health Promotion; 17-21 November; Geneva; 1986.

6. World Health Organization. The Jakarta Declaration on leading health promotion into the 21st century. World Health Organization; 1997.

7. South African National Department of Health. Eye Health Policy Framework and Strategy 2017-2022. South African National Department of Health; October 2016.

8. Ntayiya $\mathrm{S}$, Mntuyedwa $\mathrm{M}$, Nomabunga $\mathrm{N}$, et al. Health promotion in a rural health district. Making it more effective and efficient. Initiative for sub-district support. The Health Systems Trust. Durban: Kwik Kopy Printing; 1998.

9. Padilla MA, Di Stefano AF. A snapshot of optometry around the world. Rev Optom 2009;146(6):n.p.

10. Singh S. A critical analysis of the provision for oral health promotion in South African Health Policy Development. Doctor of Philosophy (Dental Public Health) Theses. University of the Western Cape; 2005.

11. Sithole HL. An overview of the National Health Insurance and its possible impact on eye healthcare services in South Africa. Afr Vision Eye Health 2015;74(1):6. https://doi.org/10.4102/aveh.v74i1.18

12. Kelleher $\mathrm{C}$. Education and training in health promotion: theory and methods. Health Pr Int 1996;11(1):47-53. https://doi.org/10.1093/heapro/11.1.47

13. Corrigan $M$, Newton JT, Gibbons DE, et al. The mouth-body split: conceptual models of oral health and their relationship to general health among ethnic minorities in South Thames Health Region. Comm Dent Health 2010;18:42-46.

14. Forrest JL, Miller SA. Enhancing your practice through evidence-based decision making. J Evid Based Dent Pract 2001;1:51-57. https://doi.org/10.1067/med.2001.116393 


\section{Appendix 1}

BOX 1-A1: Summary of interview questions for national health managers. Is there any policy on eye health promotion in the country?

Do you believe that eye health promotion or some elements of eye health promotion can be integrated in your programme?

How would you envisage such an integrated programme?

Is there adequate capacity for the roll-out of eye health promotion messages in the country?

How can you provide support for eye health promotion in the communities?
BOX 2-A1: Summary of interview questions for provincial health managers.

Is it possible to integrate eye health promotion messages into those in other health directorates?

What are the possible ways of getting support to integrate eye health promotion messages?

What could be the specific barriers to integrating health programmes? 